\title{
The Effect of Coordinative Locomotor Training Using Elastic Bands on the Flexibility and Body Alignment of Elementary School Right-Handed Baseball Players
}

Mobeom Jeong

Chung-Yeon Korean Medicine Hospital, Gwangju, Republic of Korea

Purpose: This study sought to identify the effects of coordinative locomotor training (CLT) using elastic bands on the flexibility and body alignment of right-handed baseball players in elementary school.

Methods: The subjects were 20 instructed right-handed baseball players in elementary school. They were classified into the experimental group with 10 players $(n=10)$ to be given coordinative locomotor training using elastic bands and the control group with 10 players $(n=10)$. Flexibility was measured by the sit and reach exercise. Body alignment was measured using formetric 4D method to measure the trunk imbalance angle (TI), trunk torsion angle (T), pelvic tilt angle (PTi), pelvic torsion angle (PTo), pelvic rotation angle (PR), kyphotic angle (Ky), and lordotic angle (Lo).

Results: There was a significant increase in the flexibility within the experimental group $(p<0.05)$. after the intervention. There was also a significant increase in the difference between the experimental group and the control group $(p<0.05)$. There was a significant decrease in PR during body alignment in the experimental group after intervention $(p<0.05)$. An analysis of the differences between groups showed a significant decrease in the PR of the experimental group compared to the control group $(p<0.05)$.

Conclusion: These findings show that coordinative locomotor training using elastic bands would be effective for enhancing the flexibility and pelvic rotation of elementary school right-handed baseball players.

Keywords: Baseball player, Body alignment, Coordinative locomotor training, Elementary school, Flexibility

서 론

초등학생 시절인 아동기는 신체적 발육 및 정서적 발달과정에서 매 우 중요한 시기이며 신체활동 같은 다양한 생활습관이 형성되는 시 기이다. 이로 인해 자신의 체형에 대한 인지와 체형 인식이 생기는 중 요한 시기이다. 자신의 체형을 잘못 인식하는 그룹에서 부정적인 운 동습관이 나타난다고 보고될 정도로 체형 인식은 중요하다. ${ }^{2}$ 체형 인 식이 바르게 되기 위해서는 자세가 중요한데, 자세는 일반적으로 사 람의 신체정렬 방식을 의미하며 척추와 사지 모두를 포함하여 신체 가 움직이는 것, 즉 움직임과 활동에 따라 깊은 관계가 있다. ${ }^{3}$ 성인보 다 성장하는 나이에 작용하는 부하에 적응 및 변형을 일으키기 쉬우 며 기능적 발달과 형태적 발육의 불균형이 나타날 수 있다. ${ }^{4}$

자세의 불균형을 가져올 수 있는 운동으로는 편측 운동이 있는데 던지기와 치기, 받기 동작이 편측 운동에 속하며 스포츠 중에서는 야
구에서 주로 사용되는 동작이다. 대중적인 인기를 모으는 야구는 2021년 현재 초등부 팀만 90팀이 대한야구협회에 집계되며 달리기, 던지기, 치기, 도약하기, 받기 등의 운동 동작을 수행한다. 그 중 던지 기가 가장 많이 사용되며 경기를 진행하는 동안에 전체 신체 활동의 약 $70 \%$ 를 차지한다. 이는 편측 형태의 운동으로 주로 사용되는 근육 의 반복 숙달로 인해 신체 좌우 근육의 불균형을 가져오며 부적절한 자세를 초래할 수 있다. ${ }^{6}$ 인체에 가해지는 지속적인 부하는 근육 뼈대 계의 변형 및 비후가 발생되며 잘못된 자세로 지속적인 활동을 하게 되면 잘못된 움직임을 초래하고 이는 습관이 되어 근육 뼈대계의 점 진적인 변화가 나타나 척추옆굽음, 척추앞굽음 그리고 척추뒷굽음증 과 같은 이상이 발생된다. 이러한 체형 변화는 운동선수에게 가장 중 요한 호흡능력의 차이가 발생된다고 보고되었다. 특히 야구선수들 의 투구동작이나 배팅 등은 특정 관절에 자극을 주어 스트레스 및 과다 사용으로 장애가 발생될 수 있고, 불균형된 근육은 골격의 형태 
적 변형과 통증을 일으키고 통증은 관절이 움직일 수 있는 범위와 능 동적 움직임을 제한하여 경기력을 저하시키며 더 악화되면 스포츠 상해로 진행되어 경기를 수행할 수 없게 되는 상황이 발생한다.

척추와 상지 사이의 해부학적, 신경 생리학적, 기능적 관계를 고려 할 때, 목쪽 및 가슴쪽 영역은 밀접한 연관이 있고, ${ }^{10}$ Young 드ㅇㅣㅡㄴ 어 깨 손상환자가 어깨너머로 던지는 동작을 할 때 해부학적으로 목이 어깨 역할을 할 수 있다고 보고하였다. 또한 등뼈 뒷굽음각 측정 수치 가 평균보다 큰 청소년 야구 선수는 안쪽 팔꿈치 부상이 발생할 확률 이 2.5 배 더 높다고 보고 하였다. ${ }^{12}$ 척추의 굽이는 정상적인 목뼈 앞굽 음 등뼈 뒷굽음 허리뼈 앞굽음의 부드러운 곡선의 형태를 가지고 있 으며 척추에 가해지는 충격을 흡수하고 척추의 근육을 움직일 수 있 도록 한다. 그러나 몸통이 앞쪽에 있을수록 허리뼈 부위와 엉덩관절 에 부하가 증가하며 골반에 지속적으로 비대칭적인 부하를 주게 되 면 엉치엉덩관절의 퇴행성 변화가 발생된다.13 엉치엉덩관절의 변위 는 목뼈와 등뼈 그리고 허리뼈 및 골반에 여러가지 복합적인 문제와 통증 일으키며 직립운동의 유연성을 제한한다. ${ }^{14}$ 척추 관절가동범위 를 결정하는 데 있어 중요한 영향을 미치는 요인은 유연성이며, ${ }^{15}$ 이러 한 유연성과 신체정렬이 팔과 다리 사용에 깊게 상호작용하며 영향 을 미친다는 개념을 뒷받침한다.

최근 생체역학, 신경과학, 운동조절 등 척추와 사지간 협응과 관련 된 임상현장에서 운동 목적으로 팔다리의 협응이 패턴인 협응이동 훈련(coordinative locomotor training, CLT)가 제공되고 있다. ${ }^{16}$ 협응이 동훈련은 달리는 사람을 나타내는 스프린터(sprinter)와 스케이트를 타는 사람 스케이터(skater)의 두 가지 형태를 통해 인체의 협응 구조 를 과학적으로 체계화시킨 훈련으로 고안하였다. ${ }^{17}$ 또한 $\mathrm{Kim}^{18}$ 의 연 구에 따르면 협응이동훈련 시 체간의 안정성에 기여하는 배근육의 강화를 강조하며 모든 자세에서 상지와 하지의 동작을 이용하여 배 근육의 수축을 유발함으로써 양궁선수들의 자세조절과 균형능력을 향상시켰다고 보고하였다. 협응이동훈련은 열린사슬운동(open kinematic), 닫힌사슬운동(closed kinematic chain)을 적용할 수 있으며 팔 과 다리의 협응적인 움직임을 이용하여 자세조절의 향상을 위한 연 구도 진행되고 있다. ${ }^{19}$ 협응이동훈련 시 부하로는 다양한 각도의 동작 자세를 실시하여도 운동 시 주어지는 충격이 최소화되어 부상에 대 한 부담 없이 훈련을 할 수 있고 선택적 저항을 줄 수 있는 탄력밴드 가사용되어왔다. ${ }^{20,21}$

체형 인식이 중요한 아동기에 운동을 시작하는 운동선수들의 유 연성 및 신체정렬의 연구는 미흡한 실정이며 대부분 척추측만증 환 자들과 일반인 성인을 대상으로 한 경우가 많았다. 16,19,22 또한 우세손 과 비우세손에 차이에 대한 연구23는 있으나 운동 및 중재 적용에 있 어 따로 구분한 연구들은 미흡한 실정이다. 이에 본 연구는 동일한 훈 련을 받는 초등학교 야구선수들 중에서 오른손잡이를 특정하여 탄
력밴드를 이용한 협응이동훈련 프로그램을 적용하고 유연성과 신체 정렬에 미치는 영향을 알아보고자 하였다.

\section{연구 방법}

\section{1. 연구대상}

본 연구는 광주광역시에 소재한 00 초등학교 야구부학생 오른손잡 이 20명을 대상으로 2019년 12월에서 2020년 1월까지 실험하였다. 난 수표를 사용하여 탄력밴드를 사용한 협응이동훈련을 실시한 실험 군(experimental group, $\mathrm{n}=10$ )과 일반훈련을 실시한 대조군(control group, $n=10)$ 을 무작위 배치하였다. 동일한 훈련을 실시하는 초등학 교 야구부를 선택하였으며 신경학적 증상이 없으며 근골격계 장애 및 기형이 없고 상지와 하지에 통증 및 운동제한이 없는 대상으로 실 시하였다. 본 연구를 진행하기 위해 실험자, 감독 및 코치에게 본 연구 의 목적과 방법을 설명하고 훈련 참여 동의서를 작성하였다(Table 1).

\section{2. 측정도구 및 방법}

1) 유연성 측정

유연성 측정은 피실험자가 맨발로 앉아 무릎을 펴서 뻗고 발목을 세 워 측정기구의 수직면에 완전히 닿도록 하여 바른 자세로 앉는다. 양 손을 모아 무릎을 편 상태로 윗몸을 앞으로 굽혀 양손을 모아 양 중 지로 최대한 앞으로 뻗어 측정기를 민다. 정지상태일 때의 기록을 측 정한다. 3 회 측정하여 평균을 낸다. 주의사항은 측정 시 반드시 무릎 을 펴져 있도록 한다. 윗몸의 반동은 배제한다. 양손가락이 같은 길이 로 내려가야한다.

\section{2) 신체정렬 측정}

신체정렬 측정 장비는 4 차원 영상분석기(Formetric $4 \mathrm{D}$, Germany)를 사용하여 측정하였다(Figure 1). 이 장비의 특징으로는 빠르고 정확 한 측정시간, 할로겐 램프 사용으로 인한 방사선 피폭 위험이 없으며, 높은 재현성과 객관적 데이터 제공 그리고 측정 결과를 통한 자세 및 척추측만증 진단이 가능하다. 촬영자세는 액세서리를 뺀 이후 대상 자는 속옷을 제외하고 상의를 탈의하고 발판 위에 올라서서 등은 측 정 장비의 카메라 쪽을 향한 후 꼬리뼈가 보일 정도까지만 하의를 내

Table 1. The general characteristics of subject

$(n=20)$

\begin{tabular}{lcccc}
\hline & $\begin{array}{c}\text { Experimental } \\
\text { group }(n=10)\end{array}$ & $\begin{array}{c}\text { Control group } \\
(n=10)\end{array}$ & $t$ & $p$ \\
\hline Age $(\mathrm{yr})$ & $11.5 \pm 1.1$ & $11.4 \pm 1.1$ & 0.190 & 0.851 \\
Height $(\mathrm{cm})$ & $140.7 \pm 10.3$ & $143.5 \pm .14 .3$ & -0.499 & 0.624 \\
Weight $(\mathrm{kg})$ & $36.3 \pm 8.9$ & $41.7 \pm 10.2$ & -0.566 & 0.578 \\
\hline
\end{tabular}

All values showed Mean \pm Standard deviation. 
리게 하였다. 4 차원 영상분석기 장비와 대상자 사이의 거리는 $2 \mathrm{~m}$ 로 하였고, 측정 자세는 몸에 힘을 빼고 양팔은 자연스럽게 내리며 시선 은 약간 아래쪽 약 $15^{\circ}$ 굽힘자세를 취한다. 무릎은 곧게 펴고 발은 어 깨 넓이로 벌린다. 이때 뒤꿈치를 측정라인에 맞추어 선다. 촬영으로 형성된 모델은 오차가 $0.05 \mathrm{~mm}$ 정도에 불과하기 때문에 등 표면의 형 태를 정확하게 분석할 수 있다. 몸통 기울기각(trunk imbalance angle), 몸통 비틀림각(trunk torsion angle), 골반 기울기각(pelvic tilt angle), 골

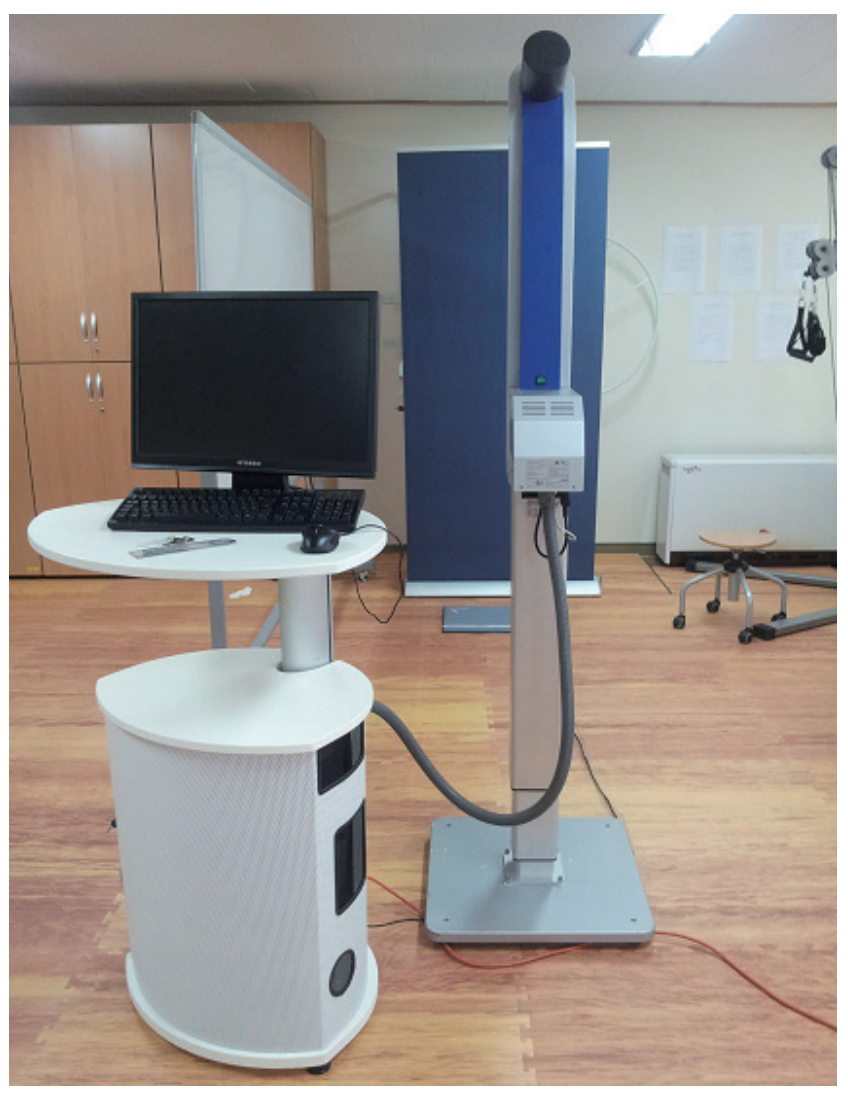

Figure 1. Formetric 4D.
반 비틀림각(pelvic torsion angle), 골반 회전각(pelvic rotation angle), 등 뼈 뒤굽음각(kyphotic angle), 허리뼈 앞굽음각(lordotic angle)을 측정 하였다. ${ }^{24}$

\section{3. 실험절차}

본 연구에서 적용된 협응이동훈련 프로그램은 $\operatorname{Dietz}^{17}$ 의 저서를 참고 하여 탄력밴드를 적용하였다. 총 하루 1 시간, 주 5 회, 4 주 동안 적용하 였고 실험군과 대조군 모두 야구부에서 시행하는 훈련 도중 실험군 만 시간을 정하여 운동치료 10 년 이상 경력이 있는 물리치료사가 그 룹으로 스프린터 스케이터 동작을 반복 실시하도록 하였다. 대조군 은 야구부의 훈련을 이어가고 훈련 중에 실험군만 중재프로그램을 적용하므로 따로 웜업(warm up)과 쿨다운(cool down) 시간을 적용하 지는 않았다.

스프린터 동작은 스탠스(stance)기에 어깨뼈의 앞쪽올림, 팔의 굽 힘과 모음, 가쪽돌림, 골반의 뒤쪽내림, 다리의 폄과 벌림, 안쪽돌림 을 실시하였으며 스윙(swing)기에 어깨뼈의 뒤쪽내림 팔의 폄과 벌림, 안쪽돌림, 골반의 앞쪽올림, 다리의 굽힘과 모음, 가쪽돌림을 실시하 였다. 스케이터 동작은 스탠스기에 어깨뼈의 앞쪽내림, 팔의 폄과 모 음, 안쪽돌림, 골반의 앞쪽내림, 다리의 폄과 모음, 가쪽돌림을 실시하 였으며 스윙기에 어깨뼈의 뒤쪽올림 팔의 굽힘과 벌림, 가쪽돌림, 골 반의 뒤쪽올림, 다리의 굽힘과 벌림, 안쪽돌림을 실시하였다(Figure 2).

\section{4. 자료분석}

연구 대상자의 일반적 특성은 기술통계를 사용해 평균과 표준편차로 제시하였다. 수집된 자료들 중에서 좌우가 나뉘어 있는 자료는 중심 을 $0^{\circ}$ 로 하여 멀어진 값을 제시하였고 정규성을 검증하기 위해 샤피 로-윌크(Shapiro-Wilk) 분석을 실시하여 모든 자료의 정규분포를 확인 하였다. 중재 전과 중재 후에 따른 유연성과 척추정렬의 차이를 알아
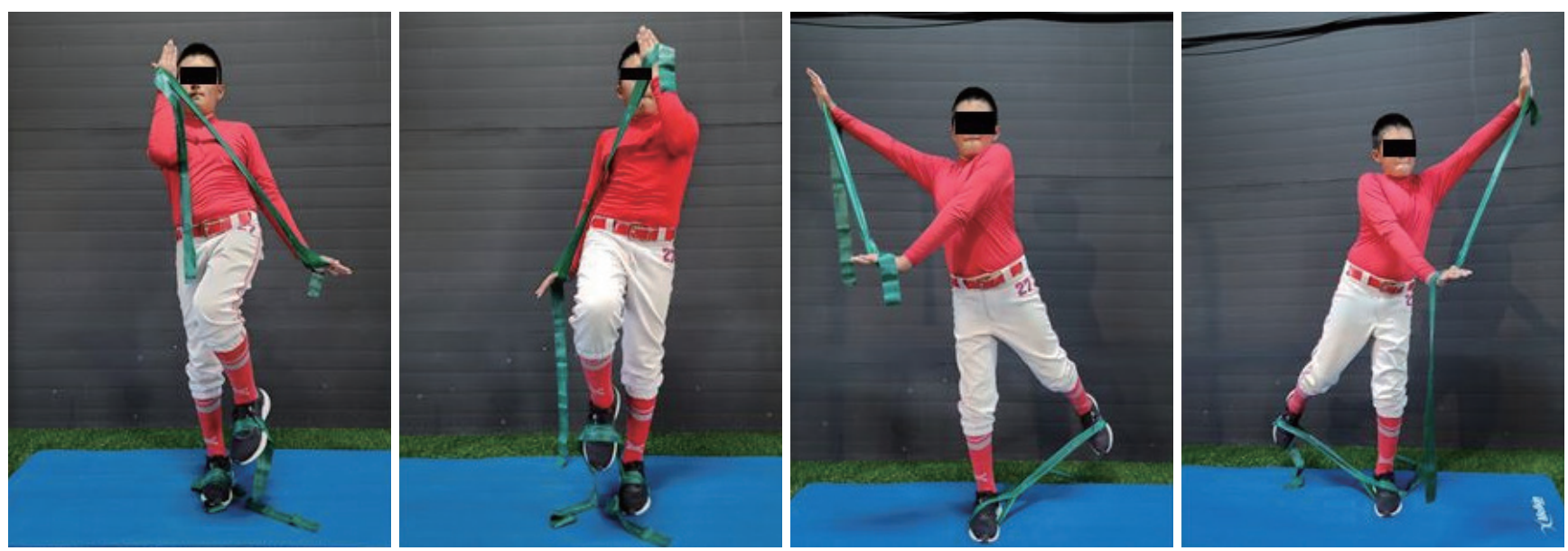

Figure 2. Coordinative Locomotor Training using Elastic Band (Sprinter \& Skater). 
Table 2. Comparison of outcome measures at flexibility $(\mathrm{cm})$

\begin{tabular}{lccccc}
\hline & $\begin{array}{c}\text { Experimental } \\
\text { group }(n=10)\end{array}$ & & $\begin{array}{c}\text { Control group } \\
(n=10)\end{array}$ & & \\
\cline { 2 - 2 } & Mean \pm SD & & Mean \pm SD & & $p$ \\
\hline Pre test & $7.43 \pm 5.56$ & & $9.95 \pm 2.86$ & & \\
Post test & $8.40 \pm 5.31$ & & $9.85 \pm 2.94$ & & \\
Pre-Post & $0.97 \pm 0.72$ & & $-0.10 \pm 0.29$ & 4.352 & $0.001^{*}$ \\
$t$ & -4.260 & & 1.078 & & \\
$p$ & $0.002^{*}$ & & 0.309 & & \\
\hline
\end{tabular}

SD: standard deviation.

${ }^{*} p<0.05$.

보기 위해 대응표본 t-검정을 실시하였고 군간 비교를 위해 독립표본 t-검정을 실시하였다. 통계처리는 Window version SPSS program 21.0을 이용하였으며 모든 통계학적 유의수준은 $\mathrm{p}<0.05$ 로 설정하였다.

\section{결 과}

\section{1. 유연성 측정}

중재 전후에 따른 유연성 측정은 실험군에서 중재 전 $7.43 \pm 5.56 \mathrm{~cm}$, $9.95 \pm 2.86 \mathrm{~cm}$ 에서 중재 후 $8.40 \pm 5.31 \mathrm{~cm}, 9.85 \pm 2.94 \mathrm{~cm}$ 로 중재 후에 통계학적으로 유의하게 증가하였다 $(\mathrm{p}<0.05)$.

중재 전후 유연성 측정의 변화량 차이 검정에서 실험군 $0.97 \pm 0.72 \mathrm{~cm}$, 대조군 $-0.10 \pm 0.29 \mathrm{~cm}$ 로 그룹 간 중재 전후 유연성 측정의 변화량차이 는 실험군이 더 높게 통계학적으로 유의한 차이가 있었다 $(\mathrm{p}<0.05)(\mathrm{Ta}-$ ble 2).

\section{2. 신체정렬 측정}

중재 전후에 따른 신체정렬 측정 중 골반 회전각은 실험군에서 중재 전 $3.66 \pm 3.04^{\circ}$ 에서 중재 후 $1.96 \pm 2.50^{\circ}$ 으로 실험군에서 중재 전에 비 해 중재 후에 통계학적으로 유의하게 감소하였다 $(\mathrm{p}<0.05)$.

중재 전후 신체정렬 측정 중 골반 회전각의 변화량 차이 검정에서 실험군 $1.69 \pm 2.01^{\circ}$, 대조군 $-0.12 \pm 1.19^{\circ}$ 로 그룹 간 중재 전후 유연성 측 정의 변화량 차이는 실험군이 더 낮게 통계학적으로 유의한 차이가 있었다 $(\mathrm{p}<0.05)($ Table 3$)$.

\section{고 찰}

척추의 해부학적 운동면에서의 편위와 회전의 정도가 정상 범주를 넘어선 경우를 비정상적 신체정렬이라 말하며 이는 반복적인 움직임 의 잘못된 수행으로 인해 관절 주변 조직의 역학적 변화를 초래하여 척추의 정렬에 부정적인 영향을 미친다고 보고되었다. ${ }^{25,26}$ 상지 동작 에서 운동조절의 핵심이 되는 요소는 양손 운동의 협응이다. ${ }^{27}$ 이는
상지의 정상적인 운동이 동작 수행의 질을 결정하는 필수 요소로 이 어진다고 할 수 있다. ${ }^{28}$ 그러나 야구에 있어 단순히 상지의 동작만으 로 투구 동작이 이루어지는 것은 아니며 하지, 체간, 상지의 각 분절 과 근육들의 협력작용이 필요하다. ${ }^{29}$ 하지에서의 추진력이 골반, 체간 을 통하여 상지로 전달될 때 어깨의 최대 각속도를 만들어낸다. ${ }^{30}$ 또 한 척추 움직임이 제한적이면 투구 동작의 후반부에 투구 안정성 유 지 능력에 영향을 준다. 이에 본 연구는 상지와 하지 그리고 체간의 움직임을 달리는 사람과 스케이트를 타는 사람의 두 가지 협응적인 움직임으로 자세조절을 향상시킬 수 있는 협응이동훈련이 본격적으 로 야구를 시작한 초등학교 오른손잡이 야구선수들의 척추 움직임 유연성과 신체정렬에 어떠한 영향을 미치는지 알아보고자 진행하였다.

본 연구에서 중재 전후에 따른 유연성 측정 결과는 실험군에서 통 계학적으로 유의하게 증가하였다 $(\mathrm{p}<0.05)$. 이는 선행연구에서 탄력 밴드를 이용한 협응이동훈련을 적용한 결과 실험 전 $8.13 \pm 3.77$ 점에 서 실험 후 $12.19 \pm 5.10$ 점으로 통계적으로 유의하게 증가한 결과와 일 치한다. ${ }^{20}$ 하지만 위의 선행연구에서는 대조군에서 탄력밴드가 없는 협응이동훈련을 적용하였고 통계적으로 유의한 증가가 있었던 반면 에 본 연구에서는 대조군에서 협응이동훈련을 적용하지 않았으며 통계적으로 유의성이 보이지 않았다. 이는 탄력밴드의 유무와 상관 없이 스프린터와 스케이터 동작의 반복된 신장과 체중을 이용한 강 화 운동을 통해 근육길이 및 근력의 불균형이 해소되어 척추의 운동 범위 증가가 유연성의 증가로 이어진 것으로 보인다. ${ }^{6}$

신체정렬 측정 중 골반 회전각에서 중재 전후에 따라 실험군에서 유의한 감소를 보였고 군 간 비교에서도 실험군이 유의한 감소를 보 였다 $(\mathrm{p}<0.05)$ 체간의 회전에 있어서 골반의 안정화 움직임을 수행할 때 배가쪽 빗근들에 비해 배곧은근은 기여도가 낮기 때문에 더 낮은 근활성도를 보여야 한다. ${ }^{31}$ 배곧은근의 활성도를 줄이기 위해서는 배 바깥빗근과 반대측 배속빗근과 배가로근의 동시 수축이 이루어지는 것이 중요하다. ${ }^{32}$ 이는 물건을 잡는 것과 같은 대부분의 일상생활이 팔과 다리의 움직임 결합된 상태로 몸통이 반복적으로 체간을 회전 하면서 이뤄지기 때문이다. ${ }^{33}$ 그러므로 배에 있는 근육들의 적절한 동원과 순서가 체간 회전을 제어하는 데 중요하다고 하였다. ${ }^{34} \mathrm{Behm}$ 등 35 은 외부 저항이 적용된 팔과 다리의 운동이 자세조절과 관련된 근육의 활동을 촉진시킨다고 보고하였다. 한쪽 팔에 저항을 적용하 면 체간의 균형에 동요가 발생하며 안정화를 유지하기 위해 반대측 배근육이 동원된다. ${ }^{31}$ 배바깥빗근, 배속빗근, 배가로근은 팔과 다리 의 움직임에 영향을 받는다고 보고되었고, ${ }^{36}$ 이는 외부저항인 탄력밴 드를 이용한 협응이동훈련의 스프린터와 스케이터 동작이 팔과 다 리의 나선형, 대각선 동작들로 체간의 회전이 가미되어 배가쪽 빗근 들의 고유수용기를 자극시키며 활성도를 높여 골반 회전각을 정상 에 가깝게 만드는 결과를 뒷받침한다. 골반의 정렬은 자세 안정성에 
Table 3. Comparison of outcome measures at body alignment

\begin{tabular}{|c|c|c|c|c|}
\hline & Experimental group $(n=10)$ & Control group $(n=10)$ & t & $n$ \\
\hline & Mean \pm SD & Mean \pm SD & $l$ & 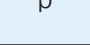 \\
\hline Trunk Imbal & & & & \\
\hline Pre test & $1.09 \pm .94$ & $1.18 \pm .82$ & & \\
\hline Post test & $1.34 \pm 1.02$ & $1.03 \pm .96$ & & \\
\hline Pre-Post & $-0.25 \pm 1.30$ & $0.15 \pm 1.12$ & -0.745 & 0.466 \\
\hline $\mathrm{t}$ & -0.618 & 0.423 & & \\
\hline $\mathrm{p}$ & 0.552 & 0.682 & & \\
\hline Trunk Torsio & & & & \\
\hline Pre test & $4.75 \pm 3.14$ & $3.83 \pm 2.70$ & & \\
\hline Post test & $7.94 \pm 7.83$ & $5.66 \pm 8.45$ & & \\
\hline Pre-Post & $-3.18 \pm 7.97$ & $-1.83 \pm 9.18$ & -0.352 & 0.729 \\
\hline $\mathrm{t}$ & -1.263 & -0.630 & & \\
\hline $\mathrm{p}$ & 0.238 & 0.544 & & \\
\hline Pelvic Tilt $\left({ }^{\circ}\right)$ & & & & \\
\hline Pre test & $0.95 \pm 1.11$ & $1.12 \pm 1.42$ & & \\
\hline Post test & $1.22 \pm 2.19$ & $1.06 \pm 1.61$ & & \\
\hline Pre-Post & $-0.27 \pm 2.47$ & $0.06 \pm 1.23$ & -0.378 & 0.710 \\
\hline $\mathrm{t}$ & -0.342 & 0.162 & & \\
\hline $\mathrm{p}$ & 0.740 & 0.875 & & \\
\hline Pelvic Torsio & & & & \\
\hline Pre test & $2.11 \pm 1.88$ & $2.05 \pm 1.77$ & & \\
\hline Post test & $1.91 \pm 2.44$ & $1.11 \pm 1.25$ & & \\
\hline Pre-Post & $0.20 \pm 1.55$ & $0.93 \pm 1.98$ & -0.911 & 0.374 \\
\hline $\mathrm{t}$ & 0.421 & 1.486 & & \\
\hline $\mathrm{p}$ & 0.684 & 0.171 & & \\
\hline Pelvic Rotati & & & & \\
\hline Pre test & $3.66 \pm 3.04$ & $3.34 \pm 2.51$ & & \\
\hline Post test & $1.96 \pm 2.50$ & $3.47 \pm 2.34$ & & \\
\hline Pre-Post & $1.69 \pm 2.01$ & $-0.12 \pm 1.19$ & 2.452 & $0.025^{*}$ \\
\hline $\mathrm{t}$ & 2.654 & -0.329 & & \\
\hline $\mathrm{p}$ & $0.026^{*}$ & 0.750 & & \\
\hline Kyphotic an & & & & \\
\hline Pre test & $38.38 \pm 13.49$ & $43.19 \pm 15.48$ & & \\
\hline Post test & $42.73 \pm 9.54$ & $42.11 \pm 13.05$ & & \\
\hline Pre-Post & $-4.35 \pm 10.94$ & $1.08 \pm 8.98$ & -1.215 & 0.240 \\
\hline $\mathrm{t}$ & -1.258 & 0.383 & & \\
\hline $\mathrm{p}$ & 0.240 & 0.711 & & \\
\hline Lodotic ang & & & & \\
\hline Pre test & $37.08 \pm 6.41$ & $39.32 \pm 8.36$ & & \\
\hline Post test & $35.64 \pm 6.75$ & $37.09 \pm 7.13$ & & \\
\hline Pre-Post & $1.144 \pm 5.18$ & $2.23 \pm 6.85$ & -0.289 & 0.776 \\
\hline $\mathrm{t}$ & 0.882 & 1.031 & & \\
\hline $\mathrm{p}$ & 0.401 & 0.329 & & \\
\hline
\end{tabular}

SD: standard deviation.

${ }^{*} \mathrm{p}<0.05$.

영향을 미치며 허리뼈 정렬에 직접적으로 영향을 줄 수 있다. ${ }^{37}$

본 연구에서 신체정렬의 다른 측정요인에서는 통계적으로 유의한 변화와 차이가 보이지 않았다( $\mathrm{p}>0.05)$. 본 연구에서 측정한 몸통 기
울기각의 통계 결과는 선행연굴의 결과와상반된 결과를 보였다. 이 는 초기 측정 값 설정 시 본 연구는 바른 정렬인 $0^{\circ}$ 에서 차이 나는 값 으로 산출하였고, 초기값이 $0^{\circ}$ 에서 크게 차이 나지 않은 본 연구의 대 
상자와 차이가 있기 때문으로 보여진다. 등뼈 뒤굽음각, 허리뼈 앞굽 음각의 결과 또한 통계적으로 유의함이 일치하지 않으나 위의 연구 에서 등뼈 뒤굽음각이 실험군에서 증가된 결과가 본 연구의 결과와 비슷하다. 또한 본 연구에서는 중재 이후 허리뼈 앞굽음각이 감소하 였는데 이는 허리뼈 앞굽음각이 연령이 증가할수록 각도가 증가하 지만 성장기의 1-13세에서 감소하는 양상이 보고된 선행연구 ${ }^{38}$ 로 결 과를 뒷받침할 수 있다. 결론적으로 탄력밴드를 이용한 협응이동훈 련은 특유의 나선형 패턴을 통해 고유수용기를 자극하고 정상반응 을 촉진하여 근의 길이나 장력에 대해서 구심성 흥분을 발사하는 근 방추나 건방추기관 등의 고유수용성 감각기에 자극을 주어 신경근 메커니즘의 반응을 끌어내어 유연성에 효과적이었음을 볼 수 있다. ${ }^{39}$ 특히 골반의 회전각은 골반의 회전 시 동원되는 배가쪽 빗근들의 활 성화와 배곧은근의 활성도 저하가 필요한데 협응이동훈련의 나선형 패턴을 통해 운동 시 지속적인 체간의 회전운동이 일어나 고유수용 기를 자극시키며 동원능력과 동원순서를 교육시킨것으로 사료된다.

이 연구의 제한점은 동일한 훈련을 받는 초등학교 야구부와 비슷 한 행동 양상을 보이는 오른손잡이를 채택하여 최대한 동질한 특성 을 가진 대상자를 뽑기 위해 노력하였지만 20명이라는 대상자의 숫 자로 일반화하기 어렵다는 것이다. 다른 선행연구 측정과 비교하였을 때 선행 연구보다 측정변인을 더 추가하였음에도 결과가 일치하지 않 음은 본 연구에서도 신체정렬의 다양한 변인을 완벽하게 파악하지 못했음에 있다. 또한 신체정렬의 변화가 이루어지기 전에 선제적인 중재를 통해 신체 부정렬을 바로잡고자 하였기에 결과값의 차이가 크지 않았다. 하지만 부적절한 자세의 움직임과 편측 운동의 명백한 위험성이 있기에 본 연구의 결과가 앞으로 운동을 해나갈 초등학교 야구선수에게 도움이 될 수 있을 것으로 사료되며, 국내 야구선수 모 두 동일 훈련을 실시할 수 없다는 현실에 비추어 보았을 때 이 연구결 과가 추후 이뤼질 연구의 기초자료가 될 수 있을 것으로 생각된다. 야 구선수뿐만 아니라 앞으로 운동을 해나가는 어린 선수들에게 바른 자세 통한 부상과 장애가 없는 선수 활동을 위해 지속적인 운동프로 그램 개발과 연구가 이루어질 수 있기를 바란다.

\section{REFERENCES}

1. Lee WH, Jung AR, Lim SY et al. Relationship between weight perception and exercise behaviors in korean elementary school students. KJGD. 2019;27(1):15-21.

2. Shirasawa T, Ochiai H, Nanri H et al. The relationship between distorted body image and lifestyle among Japanese adolescents: a populationbased study. Arch Public Health. 2015;73(1):1-7.

3. Goo BW, Lee MY. Comparison of postural control ability according to the various video contents during action observations. J Kor Phys Ther. 2021;33(1):16-20.
4. Ahn YD, Kim JI, Shin JH. A longitudinal study on changes in physical fitness and morphological proportionality in hockey players. KJGD. 2009;17(4):211-9.

5. Park JY, Cho JH. The analysis of foot pressure distribution according to ball speed in baseball pitching. Korean J Sports Med. 2008;26(1):71-7.

6. Kang TW, Kim BR. The effects of stretching and strengthening exercise on the pain, pelvic tilt, functional disability index, and balance ability of patients with chronic lower back pain. J Kor Phys Ther. 2019;31(1):7-12.

7. Yoo JC, Suh SW, Jung BJ et al. Asymmetric exercise and scoliosis - a study on volleyball athletes. J Korean Orthop Assoc. 2001;36(5):455-60.

8. Kang DY, Cheon SM, Son HR et al. Effects of sagittal spinopelvic alignment on motor symptom and respiratory function in mild to moderate parkinson's disease. J Kor Phys Ther. 2019;31(2):122-8.

9. Park CG. The study of low back pain self-awareness scale and spinal lateral deformity between unilateral exercise athletics in adolescents. IJCS. 2010;12(3):139-44.

10. Yeo SS, Kwon JW. A comparison study of cervical flexion-relaxation ratio in the normal and forward head postures. J Kor Phys Ther. 2020; 32(6):378-82.

11. Young JL, Herring SA, Press JM et al. The influence of the spine on the shoulder in the throwing athlete. J Back Musculoskelet Rehabil. 1996; 7(1):5-17.

12. Sakata J, Nakamura E, Suzukawa M et al. Physical risk factors for a medial elbow injury in junior baseball players: a prospective cohort study of 353 players. Am J Sports Med. 2017;45(1):135-43.

13. Kim CH, Han JT. Comparison of lumbopelvic motions during hip medial rotation depending on sex differences and chronic lower back pain. J Kor Phys Ther. 2019;31(2):117-21.

14. Park CH. Effect of chiropractic and sports massage in sacroiliac joint subluxation patients in sacroiliac joint subluxation patients. Mokwon University. Dissertation of Master's Degree. 2002.

15. Pearcy MJ, Tibrewal SB. Axial rotation and lateral bending in the normal lumbar spine measured by three-dimensional radiography. Spine. 1984; 9(6):582-7.

16. Kim JC, Lim JH. The effects of coordinative locomotor training on coordination and gait in chronic stroke patients: a randomized controlled pilot trial. J Exerc Rehabil. 2018;14(6):1010.

17. Dietz B. Let's sprint, let's skate. Innovationen im PNF-Konzept. Heidelberg, Spinger, 2009.

18. Kim JP. The effect of balance exercise on postural control and shooting record in archers. KJSB. 2008;18(2):64-74.

19. Park TJ, Park HK, Kim JM. The effects of PNF arm patterns on activation of leg muscles according to open and closed kinemetic chains. Korean Soc Phys Med. 2011;6(2):215-23.

20. Cho WS, Park SJ, Choi AY. The effect of coordinative locomotor training with elastic band on balance and flexibility in elementary school baseball players. KCS. 2019;10(7):261-6.

21. Park SJ, Park CB, Kim YS. The effects of coordinative locomotor training with elastic bands on the body alignment of elementary school baseball players. PNF \& Mov. 2019;17(3):411-9.

22. Shin SS, Song CH. The effect of lumbar stabilization exercise on the static balance of adolescent idiopathic scoliosis. Korean J Sports Med. 2007; 25(2):165-73.

23. Assmann M, Steinmetz G, Schilling AF et al. Comparison of grip 
strength in recreational climbers and non-climbing athletes-a crosssectional study. Int J Environ Res Public Health. 2021;18(1):129.

24. Schulte TL, Hierholzer E, Boerke A et al. Raster stereography versus radiography in the long-term follow-up of idiopathic scoliosis. J Spinal Disord Tec. 2008;21(1):23-8.

25. Lee J, Kim JC. The coordinative locomotor training intervention strategy using the icf tool to improve the standing posture in scoliosis: a case report. J Kor Phys Ther. 2021;33(1):7-15.

26. Sim GS, Shin HJ, Kim SY. Effects of pilates reformer exercise on standing postural alignment. J Kor Phys Ther. 2021;33(2):76-83.

27. Weigelt M. Re-examining structural constraints on the initiation of bimanual movements: the role of starting locations, movement amplitudes, and target locations. Hum Mov Sci. 2007;26(2):212-25.

28. Page SJ, Elovic E, Levine P et al. Modified constraint-induced therapy and botulinum toxin A: a promising combination. Am J Phys Med Rehabil. 2003;82(1):76-80.

29. Fleisig GS, Andrews JR, Dillman CJ et al. Kinetics of baseball pitching with implications about injury mechanisms. Am J Sports Med. 1995;23 (2):233-9.

30. Fleising U. The ethology of mythical images in healthcare biotechnology: a methodological approach to uncovering ritualized behavior in the evolution of sickness and healing. Anthropol Med. 2000;7(2):227-50.

31. Yun SJ, Kim JH. Effect of shoulder abduction angles on EMG activity of the abdominal muscles during single leg holding on the foam roller. J
Kor Phys Ther. 2020;32(4):228-32.

32. Sahrmann S. Diagnosis and treatment of movement impairment syndromes. Oxford, Elsevier Health Sciences, 2001:69-73.

33. Van Dillen LR, Sahrmann SA, Norton BJ et al. Reliability of physical examination items used for classification of patients with low back pain. Phys Ther. 1998;78(9):979-88.

34. Kisner C, Colby L. Therapeutic exercise: Foundations and techniques. Philadelphia, FA Davis, 2007.

35. Behm DG, Leonard AM, Young WB et al. Trunk muscle electromyographic activity with unstable and unilateral exercises. J Strength Cond Res. 2005;19(1):193-201.

36. Yun SJ, Kim MH. Effects of shoulder abduction in opposite directions on EMG activity in the abdominal muscles during single leg raising in the supine position on the foam roller in healthy subjects. J Kor Phys Ther. 2015;27(4):270-4.

37. Ha SM, Jeon IC. Reliability and validity of measurement using smart phone-based goniometer on pelvic tilting angle in standing and sitting position. J Kor Phys Ther. 2019;31(1):35-9.

38. Cil A, Yazici M, Uzumcugil A et al. The evolution of sagittal segmental alignment of the spine during childhood. Spine. 2005;30(1):93-100.

39. Bae SS, Kim K, Choi YW. Clinical facilitation with proprioceptive neuromuscular facilitation for functional activities. J Korean Soc Phys Med. 2006;1(1):117-23 